\title{
Study of Blood Parasites in Mabuya sp Lizards and Buforegularis Toads in Jebel Awlia and Tuti Island of Khartoum, Sudan
}

\author{
Mukhtar Hassan $^{1}$, Sara A. K. Saeed ${ }^{2}$ and Omran F. Osman ${ }^{1}$ \\ 1. Department of Zoology, Faculty of Science, University of Khartoum, Khartoum 13311, Sudan \\ 2. Natural History Museum, Faculty of Science, University of Khartoum, Khartoum 13311, Sudan
}

Received: November 20, 2014 / Accepted: December 20, 2014 / Published: January 25, 2015.

\begin{abstract}
Toads and lizards have been a part of our ecosystems for millions of years and they are good indicators of environmental health. Toads and lizards can be infected by different types of parasites; blood parasites are one of the most important parasites. The present study was conducted to survey and identify different blood parasites in Mabuya sp. lizard and Buforegularis toad in two locations in Khartoum state. Fifteen samples of Mabuya sp and fifteen samples of Buforegularis were collected. All Toads and lizards were dissected and tissue from spleen and liver were examined. The microscopic diagnosis detected Sauroleishmania and Haemogregarina spp parasites in both Mabuya and B. regularis while Microfilariae spp was detected in Mabuya sp. Trypanosoma spp was detected in only one specimen of B. regularis. The results also indicated Sauroleishmania parasites and Haemogregarina spp parasites in the sampled toads and lizards in the two locations. The study of blood parasites and their effects in diversity and health of toads and lizards is necessary to determine the impacts of infections in these animals and the use of the results as indicator of hemoparasites in the environmental as well as the food chain.
\end{abstract}

Key words: Blood Parasites, Toads, Lizards, Sudan.

\section{Introduction}

The reptiles and amphibians can be infected by different types of parasites. These parasites can be divided into enteric parasites and ectoparasites. Enteric parasites include protozoa, flagellates, ciliates, opalinids, amoebae, and coccidea. Also they can be infected by bacteria from ectoparasites like mites and ticks [1].

Blood parasites are particularly important and divers class of parasites in amphibians and reptiles. Blood parasites are classified into extracorpuscler such as Trypanosoma, Leptomonas, Leishmania, and nematodes, and intercorpuscular parasites such as many telosporidian species of the suborder Adeleiing

Correspondence author: Mukhtar Hassan, B.Sc., research fields: zoology and parasitology. E-mail: mukhtar.m.hassan87@gmail.com; Mok87bigman@gmail.com. belonging to the genera Karyolysus, Hepatozoon and Haemogregarina [2].

The Leishmania parasites are classified into three subgenera, the subgenera Leishmania (Leishmania), Leishmania (Viannia) and Leishmania (Sauroleishmania) or Lizard' leishmania, which is transmitted by the sandflies of Sergntomyia spp [3]. The Sauroleishmania has been reported in the peripheral blood of reptiles, primarily in lizards [4]. The lizard leishmania (Sauroleishmania) is one of special evolutionary interests since it has been postulated that it provides convincing evidence of evolution that an invertebrate parasite has become adapted to life in a vertebrate host [5].

Reptiles and Amphibians also can be infected by Trypanosoma, these parasites may be found extracellularly in the peripheral blood. They are transmitted by blood-sucking arthropods in terrestrial 
reptiles, and by leeches in aquatic reptiles. Although trypanosomiasis can cause severe parasitemia, it is commonly associated with lifelong subclinical infection [6].

One of the common blood parasites the family Haemogregarindae, has many species common in turtle, fishes, lizards, birds, frogs, toads and other amphibian and reptiles. Many of species are pathogenic. Such as Haemogregarina stepanowi species, which infect the turtle and a leach, and there are seven species of the genus Haemogregarina which have been described as the toad host Bufo regularis.

In Sudan three species of haemogregarines have been found in toads ( $H$. boueti, $H$. faiyumensis and $H$. aegyptia), the distribution of $H$. faiyumensis has been suggested to be restricted to the Faiyum province, (Egypt) [7].

Various genera of filaridae worms can be found in reptiles. Some of which are specific, such as Macdoualdius spp which have been detected in some species of snake and lizards, Saurositus spp which have been detected in lacertid lizards, Foleyella spp which have been detected in some species of chameleons lizards, and cardinema spp which have been detected in chelonians lizards [6]. Microfilariae are transmitted by blood sucking mosquitoes or ticks or some sandfly species such as Phlebotomus duboscqi. In Sudan [8], reported filarial in toads (Bufo regulairs), lizard (Agama colonorum), and a bat (Megaderma frons).

Due to the lack of knowledge regarding the zoonoses diseases of reptiles and amphibian in the Sudan, there is a great need to identify those parasites firstly in order to know their zoonoses importance. Thus the present study was conducted to carry out the following:

Survey of different blood parasites in reptiles and amphibians, identify types of blood parasites in two lizards' species (Mabuya striata, Mobuya quinquetaeniatus) and Bufo regularis toads and comparison of blood parasites in reptiles and amphibians according to microscopic diagnosis.

\section{Material and Method}

The samples were collected from two locations in Khartoum state; Tuti Island which lies in the union of the Blue and the White Nile and Jebel Awlyia area near the White Nile in Khartoum south. Fifteen lizards belong to species Mabuya striata (13 specimens) and Mobuya quinquetaeniatus (2 specimens), fifteen toads' specimens from species Bufo regularis were captured during this study. Tissue from spleen and liver were spotted on slides, fixed with absolute methanol, air dried, stained with Giemsa, and examined under light microscope with oil emersion lens to search for parasites. Then the positive slides were photographed using a microscope digital camera (DCE-2). The identification for microfilaria nematodes were done according to the characteristics described by [9]., identification for Sauro-Leishmania amastigotes was performed according to Paperna et al., 2001, and the identification for Haemogregarina spp was documented based on the work described by [10].

\section{Result}

The microscopic diagnosis detected Sauroleishmania and Haemogregarina spp parasites in both Mabuya and $B$. regularis while Microfilariae spp was detected in Mabuya sp. Trypanosoma spp was detected in only one specimen of $B$. regularis. The results also indicated Sauroleishmania parasites and Haemogregarina spp parasites in the sampled toads and lizards in the two locations.

\section{Discussion}

This study detected a variety of blood parasites of kinitoplastids protozoa, Haemogregarina spp, and Microfilaria spp. in Bufo regularis toad, and Mabuya spp lizards.

Bufo regularis showed more diversified parasite species compared with the lizards. This may attributed to the nature and behaviour of the toad that lives in both aquatic and terrestrial environments. 


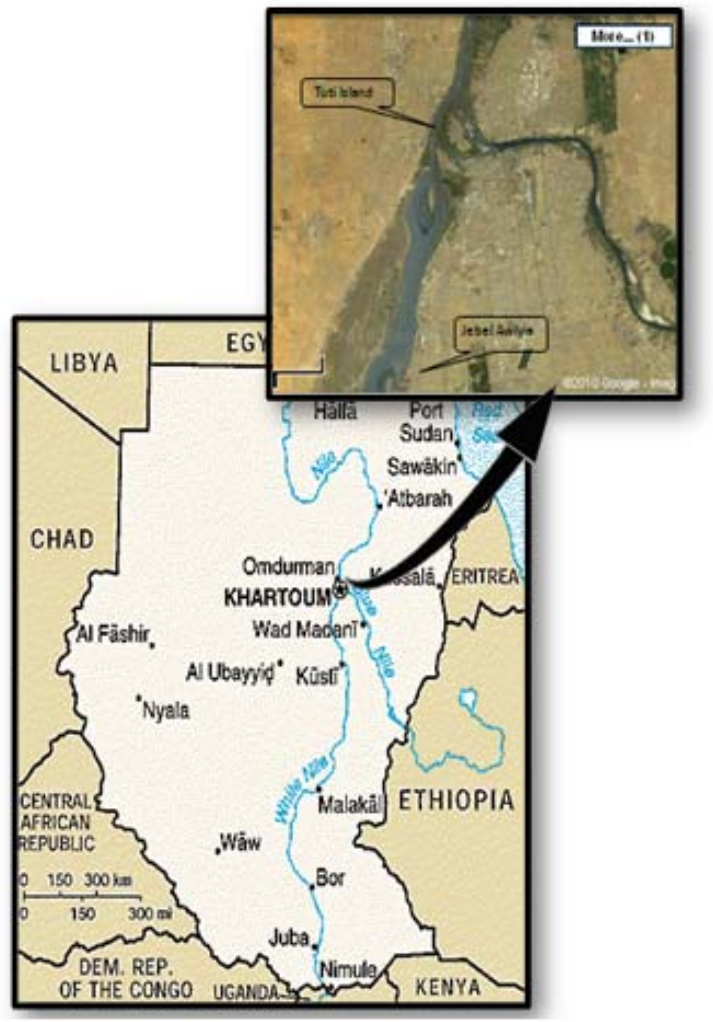

Fig. 1 Satellite image showing the location of the two study areas in Khartoum.

Table 1 The intensity of different parasites in lizards and toad species.

\begin{tabular}{llll}
\hline Parasites & $\begin{array}{l}\text { Toad } \\
\text { Bufo regularis } \\
(\mathrm{n}=15)\end{array}$ & $\begin{array}{l}\text { Mobuya striatus } \\
(\mathrm{n}=13)\end{array}$ & $\begin{array}{l}\text { Lobuya quinquetaeniatus } \\
(\mathrm{n}=2)\end{array}$ \\
\hline Sauroleishmania spp & $13.33 \%(2)$ & $61.53 \%(8)$ & 0.00 \\
Haemogregarina spp & $33.33 \%(5)$ & $7.69 \%(1)$ & 0.00 \\
Microfilaria spp & 0.00 & 0.00 & $100 \%(2)$ \\
Trypanosome spp & $6.66 \%(1)$ & 0.00 & 0.00 \\
\hline
\end{tabular}

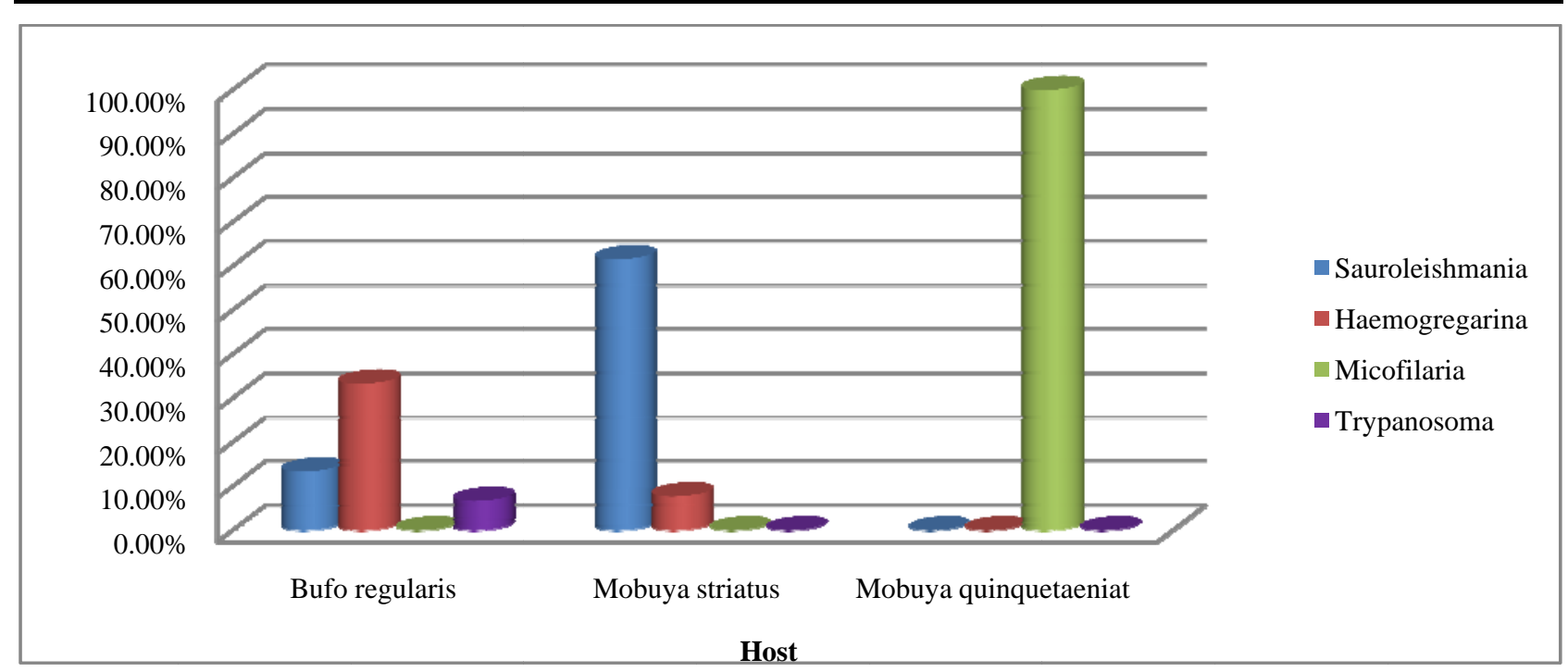

Fig. 2 The percentage of the haemoparasites in compare with hosts. 

Awlia and Tuti Island of Khartoum, Sudan

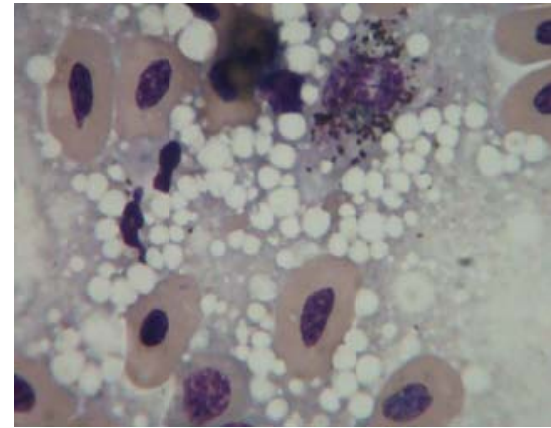

(a)

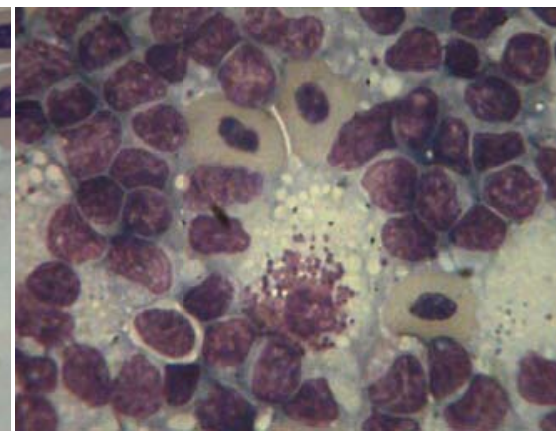

(b)

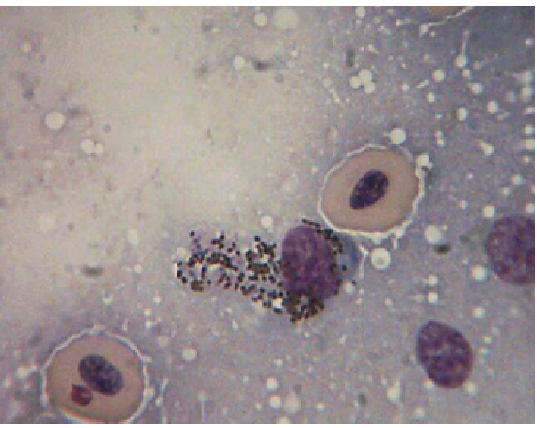

(c)

Fig. 3 WBCs rupture in lizard species Mobuya striatus showing amastigotes stage of Sauroleishmania spp.

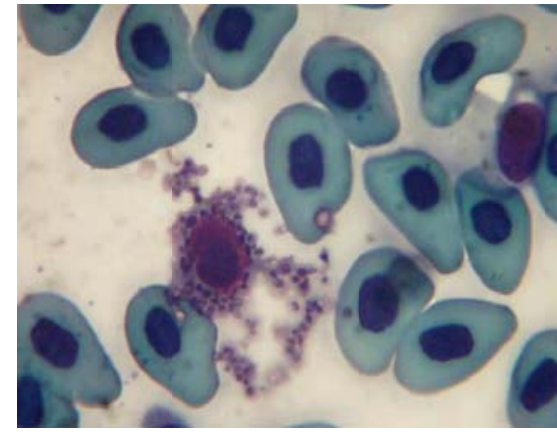

(a)

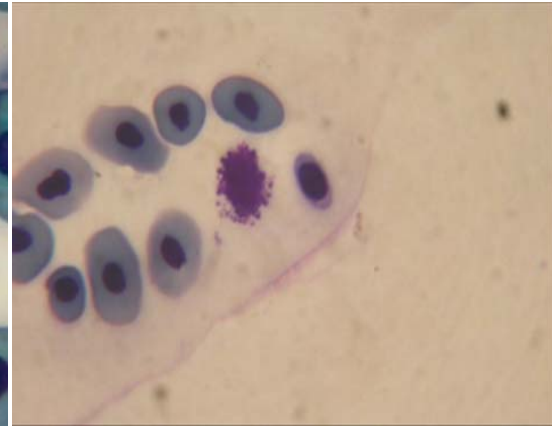

(b)

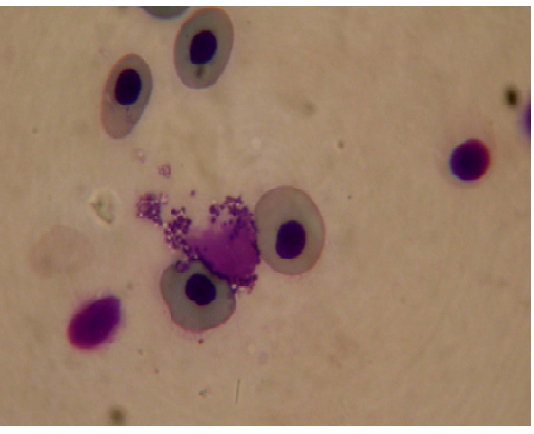

(c)

Fig .4 The amastigotes in toad species of Bufo regularis.

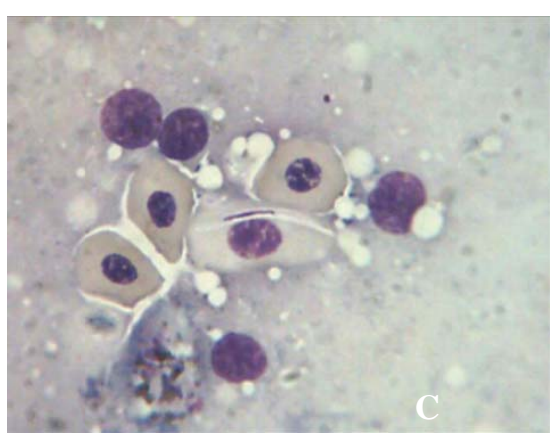

(a)

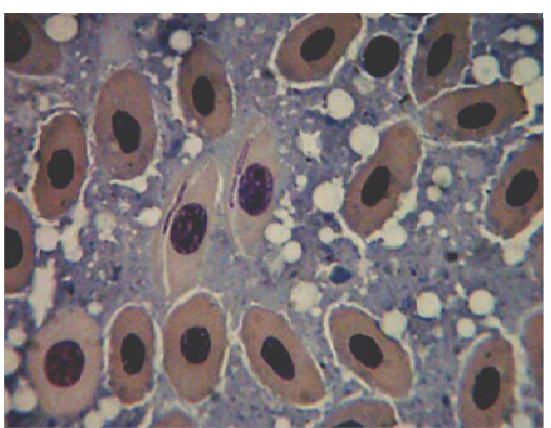

(b)

Fig. 5 The Haemogregarina species in lizards species in Mobuya striatus.

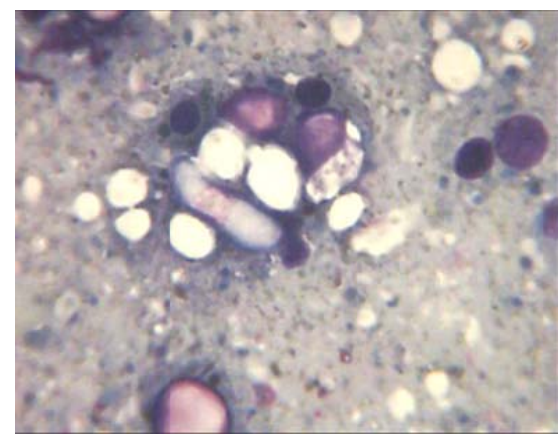

(a)

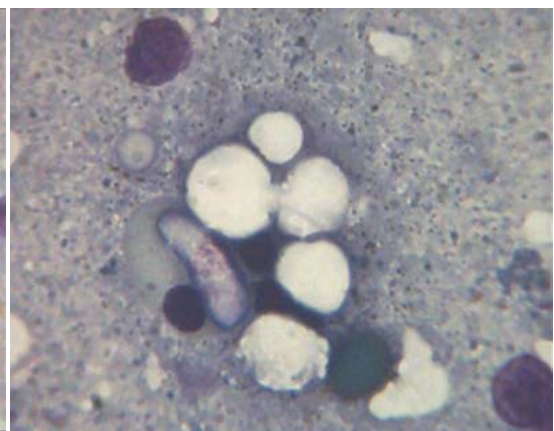

(b)

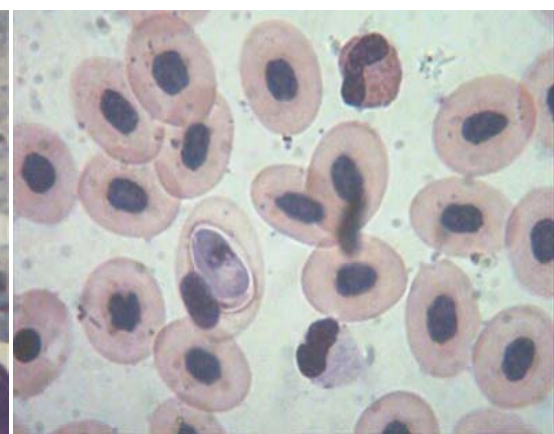

(c)

Fig .6 The gamonts stages in Haemogregarina species in toad Bufo regularis. 


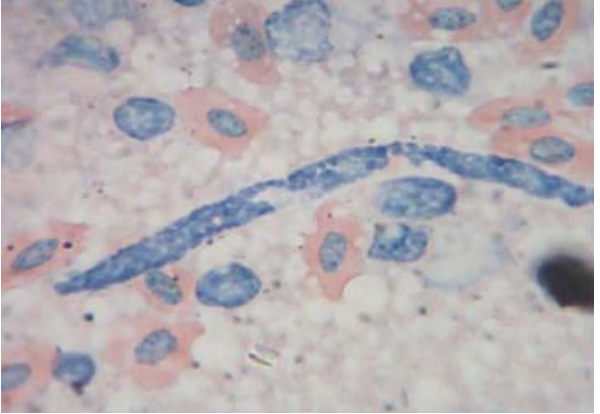

(a)

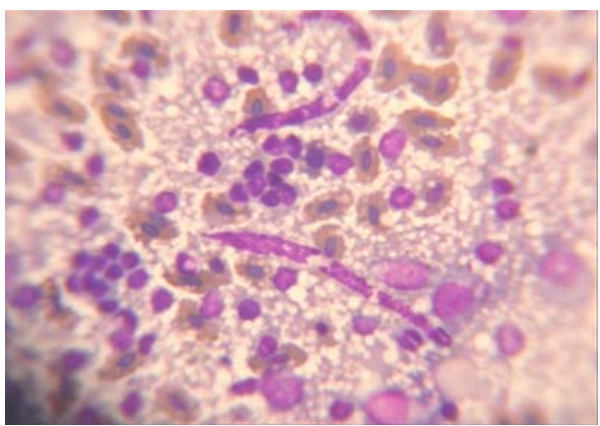

(c)

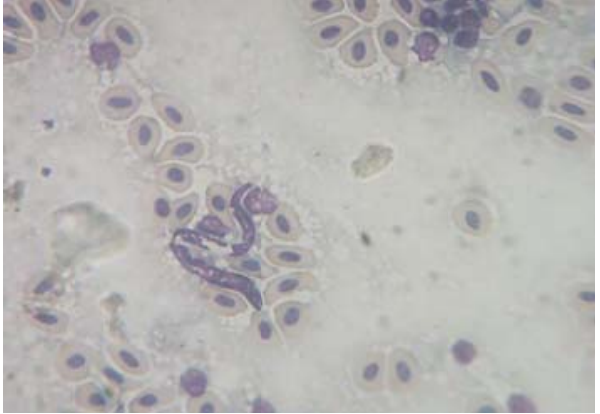

(b)

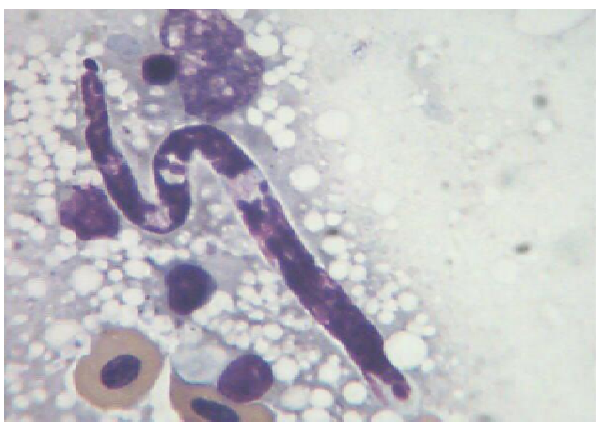

(d)

Fig.7 The microfilaria species in lizard species of Mobuya quinquetaeniatus.

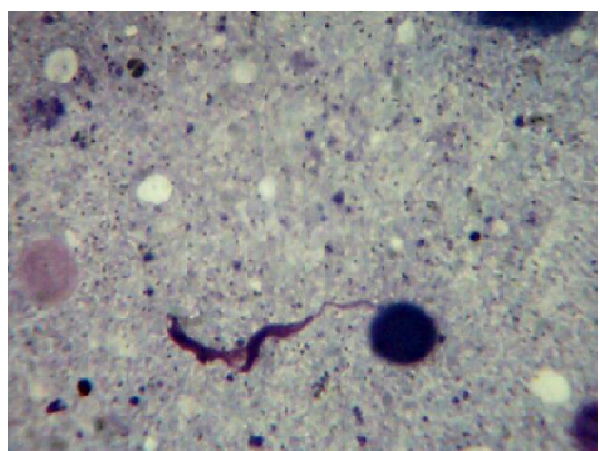

Fig. 8 The Trypanosoma species in toad Bufo regularis.

\section{Conclusion}

Indisputably, more of the unknown zoonotic diseases will emerge in the future, thus using direct and indirect methods for detecting the causative agents will contribute to the early detection of these zoonotic diseases and thus aid in their combating.

\section{References}

[1] "De la Navarre. 2009. "Common Parasitic Diseases of Reptiles and Amphibian.” Canadian Vet. http://www.K2publishing.ca.

[2] Reichenow, E. 1953. "Lehrbuch der protozoenkund." 6th edition. Begrundet von F. Doflein. G. Fischer, Jena.
[3] Chappuis, F., Sundar, S., Hailu, A., Ghalib, H., Rijal, S., Peeling, R. W., Alvar, J., and Boelaert, M. 2007. "Visceral Leishmaniasis: What are the Needs for Diagnosis, Treatment and Control?” Nature Reviews Microbiology, Vol. 13, S7-S16.

[4] Keymer, I. F. 1981. "Protozoa: In: Diseases of Reptiles, eds. Cooper JE, Jackson Of, Vol. 1, pp. 264-253. Academic Press, San Diego, CA, 1981.

[5] Hoare, C. A. 1948. "The Relationship of the Haemoflagellates.” In Proceeding of the Fourth International Congress of Tropical Medicine and Malaria, 1110-11.

[6] Lane, T. J., and Mader, D. R. 1996. "Parasitology.” Reptile Medicine and surgery. Edited by Mader, D. R. W. B. Saunders Co., Philadelphia, Pennsylvania, 185-203.

[7] Mohammed, A. H., and Mansour, S. N. 1966. "Haemogregarina Faiyumensis sp. in the Toad Bufo Regularis in Egypt.” The journal of Protozology 13 (2): 269-71.

[8] Wenyon, C. M. 1926. Protozoology. England: Baillere, Tindall, and Cox.

[9] Bain, O., Petit, G., Paperna, I., Finkelman, S., and Killick K. M. 1992. "A New Filaria of a Lizard Transmitted by Sand Flies.” Mem. Inst. Oswaldo Cruz 87 (1): 21-29.

[10] Elwasila, M. 1989. "Haemogregarina sp. (Apicomplexa: Adeleorina) from the Gecko Tarentola Annularis in the Sudan: Fine Structure and Life Cycle Trials.” Parasitology Research 75: 444-8. 